\title{
Psychological underpinnings of criminal behaviour
}

\begin{abstract}
Criminal behaviour is on a rampant rise in India. It is extremely complex to understand its genesis. The current study focuses on reviewing the available literature to highlight the role of psychological factors in the predisposition towards engaging in such behaviour which primarily includes personality, psychiatric conditions, intelligence, emotional style, need for achievement and self-control. These factors interact with each other to produce varying degrees of behaviour.
\end{abstract}

Keywords: psychological, underpinning, criminal behaviour, India
Volume 5 Issue 3 - 2017

\author{
Mehak Sikand,' Jayasankara Reddy K² \\ 'Department of Clinical Psychology, Dr. Ram Manohar Lohia \\ Hospital, India \\ ${ }^{2}$ Department of Psychology, Christ University, India
}

Correspondence: Jayasankara Reddy K, Department of

Psychology, Christ University, Hosur Road, Bangalore -560 029,

Karnataka, India, Tel 918040129682 ,

Email jayasankara.reddy@gmail.com

Received: July 21, 2017 | Published: September 12, 2017

\section{Introduction}

"Don't become a mere recorder of facts, but try to penetrate the mystery of their origin" (Ivan Pavlov as cited in Alcorn, 2009, p. 77). Criminal behaviour in the wider context of antisocial behaviour can be equated with delinquency, antisocial personality disorder and traits of aggression and impulsivity. ${ }^{1}$ There has been a rampant rise in the crime rate in India over the past decade. According to the report published by the National Crime Record Bureau in 2015, the crime rate is 581.1 per 100,000 of the population. Crimes against children have risen 5.3 percent since 2014 and there has been an increase of 2.5 percent as in other sexual offenses against women. As emphasized by Pavlov, mere information is not beneficial for the scientific and social community, going into the depth of the reason for such increase in statistics can help in formulation preventive measures. Criminal behaviour is extremely complex to understand its genesis completely. There are numerous underlying facets which do not exist in a vacuum. These factors interact with each other to produce varying degrees of behaviour. However, the emphasis of researchers has been to extract individual contributing factors and then view their contributory effects.

\section{Results and discussion}

Ysenck proposed that "criminal behaviour is the result of an interaction between certain environmental conditions and features of the nervous system". ${ }^{2} \mathrm{He}$ suggested that individuals who engage in criminal behaviour are influenced by the combination of environmental, neurobiological and personality factors, not born. This hypothesis has been studied by researchers around the globe and has been confirmed by most. Personality traits contribute to one's tendency to engage in criminal behaviour. Levine et al., ${ }^{3}$ found that psychoticism predicted self-reported delinquency whereas high psychoticism and neuroticism predicted under socialization.

They conducted a subsequent study which provided acceptable evidence of the concurrent validity of these primary scales with Self Reported Delinquency. ${ }^{3}$ Consistent with these findings, in one study NEO Five Factor Inventory was administered on 54 detained, mentally disordered offenders, and found that high neuroticism, low extroversion, and low agreeableness were found to be correlated to criminal behaviour. ${ }^{4,5}$ There is a certain amount of disagreement amongst researchers when it comes to the presence of the three personality factors among those who engage in criminal behaviour. While some state that all three elements are high in these individuals, others have found low scores on the extraversion domain. However, most research that has been conducted has found elevated levels of neuroticism.

In support of the above statement, in a comprehensive research study, Mottus found that the chances of committing an offense were also raised by low agreeableness and conscientiousness and high neuroticism. ${ }^{6}$ Apart from traits, psychopathology is also closely associated with criminal behavior. Antisocial personality disorder has been found to be highly prevalent amongst prisoners. Not only does it affect one's behavior, but also the age and severity. ${ }^{7,8}$ Personality is crucial to understand the behaviour of offenders and can further help in conceptualizing therapeutic modules. In addition to personality factors, other individual variables like intelligence, emotional behaviour, and academic achievements also determine the chances of an individual to indulge in criminal behaviour. "Individual Differences in Young Offender Emotional Behaviour" was studied by Clarbouret al., ${ }^{9}$ which confirmed social anxiety, malevolent aggression, and selfesteem as the three emotional style factors in young offenders. Lower scores on malevolent aggression and higher scores on social anxiety and social self-esteem were found to be significantly associated with first police contact later in life.

The three scales were also found to relate methodically and predictably to a range of other personality and emotional style levels. ${ }^{9}$ It has also been found that serious delinquents with low IQ committed more delinquent acts than higher IQ dangerous offenders. It was also found that the ones with lower IQ exhibited the highest levels of cognitive and behavioural impulsivity, and compared with higher IQ serious delinquents, low IQ serious delinquents were exposed to more risk factors, such as low academic achievement, being old for grade, depressed mood and poor housing. ${ }^{10,11}$ This encompasses emotional intelligence as well which has been seen to be significantly lower in people who have committed a crime..$^{12,13}$ In the Indian context, criminal behaviour has been associated with higher scores on intelligence, impulsivity, suspiciousness, self-sufficiency and lower scores in emotional stability in those with a criminal record than average population. ${ }^{14}$ 


\section{Conclusion}

Conclusively, the role of psychological factors is evident in criminal behaviour. Conceptualizations that focus on a multitude of factors including personality traits, co morbid psychiatric conditions, attitudes and cognitions, affective component and motivation can further facilitate management of the risk factors as well as interventions. ${ }^{15-28}$

\section{Acknowledgments}

None.

\section{Conflicts of interest}

The author declares there are no conflicts of interest.

\section{References}

1. Jones CM. Genetic and environmental influences on criminal behavior Rochester institute of technology, USA. 2005.

2. Bartol AM, Bartol CA. Criminal behavior: A psychosocial approach Pearson Prentice Hall, USA; 2005: 1-632.

3. Levine SZ, Jackson CJ. Eysenck's theory of crime revisited: factors or primary scales?. legal and criminological psychology. 2004;9(1):135152.

4. Egan V, McMurran M, Richardson C, et al. Criminal cognitions and personality: what does the PICTS really measure?. Criminal Behaviour and Mental Health. 200010(3):170-184.

5. Singh UP, Singh LB, Sinha B, et al. Extraversion, neuroticism, and criminality: A comparitive study of different criminal groups. Indian Journal of Social Work. 1985;259-265.

6. Mottus R, Guljajev J, Allik J, et al. Longitudinal associations of cognitive ability, personality traits and school grades with antisocial behaviour. European Journal of Personality. 2011;26(1):56-62.

7. Black DW, Gunter T, Loveless P, et al. Antisocial personality disorder in incarcerated offenders: Psychiatric comorbidity and quality of life. Ann Clin Psychiatry. 2010;22(2):113-120.

8. Fridell M, Hesse M, Jaeger MM, et al. Antisocial personality disorder as a predictor of criminal behaviour in a longitudinal study of a cohort of abusers of several classes of drugs: Relation to type of substance and type of crime. Addict Behav. 2008;33(6):799-811.

9. Clarbour J, Roger D, Miles JN, et al. Individual differences in young offender emotional behaviour. Legal and Criminological Psychology. 2009; 14(2):227-240.

10. Koolhof R, Loeber R, Wei EH, et al. Inhibiton deficits of serious delinquent boys of low intelligence. Crim Behav Ment Health. 2007;17(5):274-292.

11. Schwartz JA, Savolainen J, Aaltonen M, et al. Intelligence and criminal behavior in a total birth cohort: An examination of functional form, dimensions of intelligence, and the nature of offending. Intelligence. 2015;51:109-118.
12. Megreya AM. Emotional intelligence and criminal behaviour. J Forensic Sci. 2015;60(1):84-88.

13. Sharma N, Prakash O, Sengar KS, et al. The relation between emotional intelligence and criminal behaviour: A study amongconvicted criminals. Ind Psychiatry J. 2015;24(1):54-58.

14. Sinha S. Personality Correlates of Criminals: A comparitive study between normal controls and criminals. Ind Psychiatry J. 2016;25(1):41-46.

15. Davison S, Janca A. Personality disorder and criminal behaviour: What is the nature of relationship. Curr Opin Psychiatry. 2012;25(1):39-45.

16. Alcorn S. A Gift of Days: The Greatest Words to Live By. Simon and Schuster, USA; 2009:1-128.

17. Conway KP, McCord J. A longitudinal examination of the relation between co-offending with violent accomplices and violent crime. Aggressive Behaviour. 2002;28(2):97-108.

18. Corno L. Peer effects on criminal behavior: evidence from the homeless. Norface Migration, UK; 2012:1-46.

19. Crime in India 2015. National crime records bureau ministry of home affairs, India. 2015;1-222.

20. Harris-McKoy D, Cui M. Parental control, adolescent delinquency, and young adult criminal behavior. Journal of Child \& Family Studies. 2013;22(6):836-843.

21. Ikäheimo $\mathrm{O}$, Laukkanen $\mathrm{M}$, Hakko $\mathrm{H}$, et al. Association of family structure to later criminality:A population-based follow-up study of adolescent psychiatric inpatients in Northern Finland. Child Psychiatry Hum Dev. 2013;44(2):233-246.

22. Johnson JG, Smailes E, Cohen P, et al. Anti-social parental behaviour, problematic parenting and aggressive offspring behaviour during adulthood: A 25 year longitudinal investigation. The British Journal of Criminology. 2004;44(6):915-930.

23. Kitchen P. Exploring the link between crime and socio-economic status in Ottawa and Saskatoon: A small-area geographical analysis. Research and Statistics Division/ Department of Justice Canada, India, 1999;1-98.

24. Leonard L. Major risk factors for antisocial and delinquent behaviour among children and youth. Public Safety Canada, Canada. 2013.

25. Molidar CE. Female gang members: A profile of aggression and victimisation. Soc Work. 1996;41(3):251-257.

26. Pabbathi LR, Naik US, Mandadi G, et al. Personality assessment of offenders and mentally ill offenders. AP J Psychological Medicine. 2014;15(1):55-59.

27. Robinson C. The Relationship between Low Socio-Economic Status \& Incarceration Rates. 1998.

28. Sousa C, Herrenkohl TI, Moylan CA, et al. Longitudinal study on the effects of child abuse and children's Exposure to domestic violence, parent-child attachments, and antisocial behavior in adolescence. $J$ Interpers Violence. 2011;26(1):111-136. 